\title{
Looking through Philippine's K to 12 Curriculum in Mathematics and Science vis-a-vis TIMSS 2015 Assessment Framework
}

\author{
Marilyn U. Balagtas ${ }^{1 *}$, Danda Crimelda B. Garcia ${ }^{2}$, Dexter C. Ngo ${ }^{3}$ \\ ${ }^{1}$ Philippine Normal University, PHILIPPINES \\ ${ }^{2}$ Rex Group of Companies, Inc., PHILIPPINES \\ ${ }^{3}$ Rex Institute for Student Excellence, Inc., PHILIPPINES
}

Received 12 January 2019 • Revised 12 April 2019 • Accepted 14 April 2019

\begin{abstract}
The Philippines implemented its educational reform commonly known as $\mathrm{K}$ to 12 Program in 2013 for Filipino learners' holistic development and global competitiveness. One indicator of the reform's effectiveness is the country's performance in international large-scale assessments like the Trends in International Mathematics and Science Study (TIMSS), if it participates again in 2019. To gauge readiness and inform decisions on its participation, this study examines the alignment of TIMSS 2015 Assessment Framework vis-à-vis the 2016 Philippine's K to 12 Curriculum in Mathematics and Science. Through curriculum mapping of experts on the competencies in the two documents, the study reveals that $\mathrm{K}$ to 12 Mathematics Grade 4 is more aligned with TIMSS 2015 Assessment Framework than that of Math Grade 8, Science Grade 4, and Science Grade 8. The study recommends continuous curriculum improvement of the Philippine's K to 12 Curriculum and implementation of relevant intervention programs and support system from different education stakeholders, including country-based publishing and testing companies to address gaps on competencies found for the country to meet international benchmarks.
\end{abstract}

Keywords: $\mathrm{K}$ to 12 mathematics curriculum, $\mathrm{K}$ to 12 science curriculum, TIMSS assessment framework, curriculum-assessment alignment

\section{INTRODUCTION}

In its unending pursuit of true academic excellence, the Philippines instituted its educational reform called K to 12 Program upon the enactment of Republic Act (RA) No. 10533 known as Enhanced Basic Education Act 2013. With the intention of uplifting the Philippine educational system, possible indicators of reform's effectiveness would be the country's participation in international educational research studies such as the Trends in International Mathematics and Science Study (TIMSS). This international large-scale assessment is periodically conducted, which could provide feedback on how the Filipino students' performance has improved over time in an international setting from the time its basic education was just 10 years to now that it is $\mathrm{K}$ to 12 .

Looking back, the Philippines has participated in the first three testing periods of TIMSS in 1995, 1999 and 2003 (Ogena, Brawner, \& Ibe, 2013: 168). Then in 2008, it participated again in the TIMSS-Advanced designed to assess students' performance in their final year of secondary schooling with special preparation in advanced mathematics and physics (Ogena, Laña, \& Sasota, 2010). TIMSS is an international large-scale assessment in mathematics and science at the fourth and eighth grades. The International Association for the Evaluation of Educational Achievement (IEA), an independent international cooperative of national research institutions and government agencies, has been conducting TIMSS, which began in 1995 and with 70 participating countries in 2015 survey (Mullis, 2013: 3).

In all cycles that Philippines participated in TIMSS, the results reveal dismal performance of the Filipino students. One explanatory factor to the Philippine's poor performance then was its 10-year basic education

(C) 2019 by the authors; licensee Modestum Ltd., UK. This article is an open access article distributed under the terms and conditions of the Creative Commons Attribution License (http://creativecommons.org/licenses/by/4.0/). $\triangle$ balagtas.mu@pnu.edu.ph (*Correspondence) 


\section{Contribution of this paper to the literature}

- This paper's contribution to literature is its illustration of a process in determining the preparation of a country in participating in international large-scale assessment through curriculum mapping. In this study for example, the extent of readiness of the Philippines to participate in the TIMSS 2019 was determined through the mapping of its recent $\mathrm{K}$ to 12 Curriculum that has been implemented by schools with the assessment competencies that were covered in TIMSS. The results of the participation of the Philippines in the TIMSS 2019 could be explained by the degree of alignment of the curriculum with the competencies covered by the international assessment. The study could also be an addition to the limited literature that can be found about the Philippine's participation in TIMSS and other international-large scale assessment.

program, which was shorter when compared to the $\mathrm{K}$ to 12 program of almost all participating countries. Hence, the Philippines has stopped temporarily from participating and transformed its basic education program instead. In 2012, the Philippines implemented the compulsory Kindergarten (RA 10157, 2012). Then in 2013, the Department of Education (DepEd), the Commission of Higher Education (CHED), and the Technical Education and Skills Development Authority (TESDA), joined efforts to successfully implement this most massive education reform in the Philippines' history. As defined in Section 10 of RA 10533, the DepEd is the government agency responsible for the design and details of the enhanced basic education curriculum but should work with CHED and TESDA to craft harmonized basic, tertiary and technical-vocational education curricula for Filipino graduates.

Moreover, the $\mathrm{K}$ to 12 Program encompasses kindergarten education for at least one (1) year, elementary education for six (6) years, and secondary education for another six (6) years. Secondary education includes junior high school for four (4) years and senior high school for two (2) years. The K to 12 Program is designed to develop holistically the Filipino learners and to equip them with the $21^{\text {st }}$ century skills to make them locally and globally competitive. It promotes a curriculum that is learner-centered, developmentally-appropriate, inclusive, relevant, responsive, contextualized and global. Pedagogical approaches that are constructivist, inquiry-based, reflective, collaborative and integrative are then used. Competencies are designed in spiral progression to ensure mastery of knowledge and skills after each level.

Since the implementation of the K to 12 Program, several initiatives have taken place to ensure its success. In the private sector, aside from the participation of private schools and institutions in the discussions on the effective implementation of the reform program, publishing companies like Rex Group of Companies, where the researchers work, also took part through production of varied learning, teaching, and assessment technologies in print or digital format that are relevant to the K to 12 Program.

All efforts from the government in the implementation of this educational reform, including those coming from the private sectors, had their first round of evaluation at the end of school year 2017-2018 as the first batch of Senior High School (SHS) students graduated after six years of the implementation of the K to 12 Program. For six more years, in school year 2023-2024, the first batch of students who have completed the whole K to 12 program would have graduated. While still in the middle phase of the implementation of the $\mathrm{K}$ to 12 program, the effectiveness of such reform should be continuously monitored and documented. The success of the program could be gauged on a lot of factors including its ability to ensure that the SHS graduates become entrepreneurs, get employed or move to higher education depending on the track they took among Academic Track, Technical-Vocational-Livelihood Track, Sports Track, and Arts and Design Track (DepEd, 2018). As indicated in Section 14 of R.A. 10533, there is a need for a mandatory evaluation and review of the $\mathrm{K}$ to 12 program to include reporting the results of the national achievement tests as one measure of quality of the program. It is emphasized in Section 15 of the law for DepEd to increase its per capita spending to attain international benchmarks as a possible gauge of the effectiveness of the educational reform.

To further test the effectiveness of such reform, DepEd has also formulated assessment policies that define the needs for the basic education students to take classroom and national examinations and participate in international large-scale assessments. In DepEd Order No. 8, s. 2015, classroom assessment is viewed as an important part of curriculum implementation as it shows students' learning progress and teachers' effectiveness in their instruction. Likewise, the DepEd Order No. 55 s. 2016 puts value on the national assessments in monitoring the Philippine educational system and the schools for public accountability. Moreover, the Deped No. 29, s 2017 underscored the importance of system assessment in the K to 12 Reform particularly in providing the bases for the implementation of the national and international large-scale assessments in determining the education system's effectiveness and efficiency. These policy guidelines on assessment are being implemented in Philippine public and private elementary and secondary schools.

In the private sector, Rex Institute for Student Excellence (RISE), the assessment company under Rex Group of Companies, also finds ways to contribute to providing indicators of the effectiveness of the K to 12 Program. As a result of its participation in the IEA's International Research Conference (IRC) in 2017 held in Czech Republic, it 
has developed assessment tools aligned with the competencies that TIMSS assesses. In doing this, it examined the alignment of the TIMSS 2015 competencies in Math and Science with those in the same areas in the Philippine K to 12 Curriculum. Specifically, the researchers in this company conducted this study to answer the following questions: 1) What is the extent of alignment of the TIMSS 2015 Mathematics Assessment Framework in Grade 4 and 8 to the Philippine K to 12 Mathematics Curriculum?; 2) What is the extent of alignment of the TIMSS 2015 Science Assessment Framework in Grade 4 and 8 to the Philippine K to 12 Science Curriculum?

It is hoped that this analysis will inform the DepEd of the level of preparedness of the Filipino students when Philippines participates in TIMSS 2019 to obtain possible indicators of the effectiveness of the educational reform introduced in the country in making the Filipino citizens globally competitive.

\section{CONCEPTUAL FRAMEWORK}

In conducting an analysis of the alignment of the Philippine K to 12 Curriculum to the TIMSS Assessment Framework, the 2016 DepEd released Mathematics and Science K to 10 curricula were examined.

The Philippine Mathematics Curriculum is conceived with the twin goals of developing students' critical thinking and problem solving. The contents are clustered into five strands: 1) Numbers and Number Sense; 2) Measurement; 3) Geometry; 4) Patterns \& Algebra; and 5) Statistics and Probability (DepEd, August 2016). The domain on Numbers and Number Sense include concepts, operations and applications of numbers. Measurement focuses on measures and applications of length, mass, weight, capacity, time, money, temperature, angles, perimeter, area, surface area, and volume. Geometry focuses on the two- and three-dimensional figures. Patterns and Algebra studies patterns, relationships, and changes among shapes and quantities. Statistics and Probability focuses on skills in data collection, organization, and interpretation including making predictions about outcomes. Each domain has content and performance standards and competencies that are developed spirally to help students' mastery as they go to higher levels of learning.

On the other hand, the Philippine Science Curriculum, which starts in Grade 3, aims to develop scientific literacy among learners through the following learning domains: 1) understanding and applying scientific knowledge in local setting as well as global context whenever possible; 2) performing scientific processes and skills; and 3) developing and demonstrating scientific attitudes and values (DepEd, August 2016). The curriculum is learnercentered, inquiry-based, and evidence-based. The contents are intertwined with processes and applied in real contexts. Concepts and skills in the different fields in Science (i.e Life Sciences, Physics, Chemistry, and Earth Sciences) are presented in spiral progression to ensure deep understanding.

Likewise, IEA has made its TIMSS Assessment Framework in 2015 for Mathematics, Numeracy and Science known to participating countries. According to Gronmo, Lindquist, Arora, and Mullis (2013: 11-27), in the TIMSS 2015 Mathematics Grade 4 and 8 and Numeracy, there were two dimensions covered: content dimension, specifying the subject matter to be assessed; and the cognitive dimension, specifying the thinking processes to be assessed. The content dimension was based on the assessment framework in the previous TIMSS but with minimal revisions to make it reflective of the current curriculum of participating countries. For the cognitive dimension, three domains were targeted such as: knowing, applying and reasoning. According to Gronmo, Lindquist, Arora, and Mullis (2013, pp 24-27), knowing refers to facts, concepts and procedures that students need to know; applying refers to use of knowledge and conceptual understanding in solving problems and answering questions; and reasoning refers to the act of solving non-routine problems, unfamiliar situations, complex contexts, or multi-step problems. The study covers only the two TIMSS assessments in mathematics (i.e. Grades $4 \& 8$ ) and excluded numeracy as there was no clear document different from the $\mathrm{K}$ to 10 mathematics curriculum to examine for this part in the Philippine context.

In Mathematics for Grade 4, TIMSS 2015 covered three domains with varying weights: Number (50\%), Geometric Shapes and Measures (35\%); and Data Display (15\%). In the Number Domain, Whole Numbers was given 25\%, Fractions and Decimals was given 15\%, and Expressions, Simple Equations, and Relationship was given $10 \%$. The contents of the rest of the domains were equally distributed. In terms of cognitive dimensions, both knowing and applying are given $40 \%$ of items while reasoning is allotted $20 \%$ only.

In Grade 8 Mathematics, four content domains in the TIMSS 2015 were tested: 1) Number (30\%); Algebra (30\%); Geometry (20\%); and Data and Chance (20\%). The competencies in the eighth grade are built on the content of the fourth grade, hence they are more complex with the assumption that the students have developed proficiency in mathematics in the lower grade. The distribution of items for the cognitive dimensions, knowing items only weighed $35 \%$, applying was still $40 \%$, and reasoning increased to $25 \%$.

In TIMSS 2015 Science Framework, the previous assessment framework was used with minor updates as well to better reflect the curricula of participating countries and current international initiatives in science education (Jones, Wheeler, \& Centurino, 2013). Similarly, TIMSS Science covered two dimensions: content and cognitive. The content domains in Science Grade 4 are: 1) Life Science (45\%), 2) Physical Science (35\%), and 3) Earth Science (20\%). In TIMSS 2015 Science Grade 8, four content domains were covered, namely: 1) Biology (35\%), 2) Chemistry (20\%); 


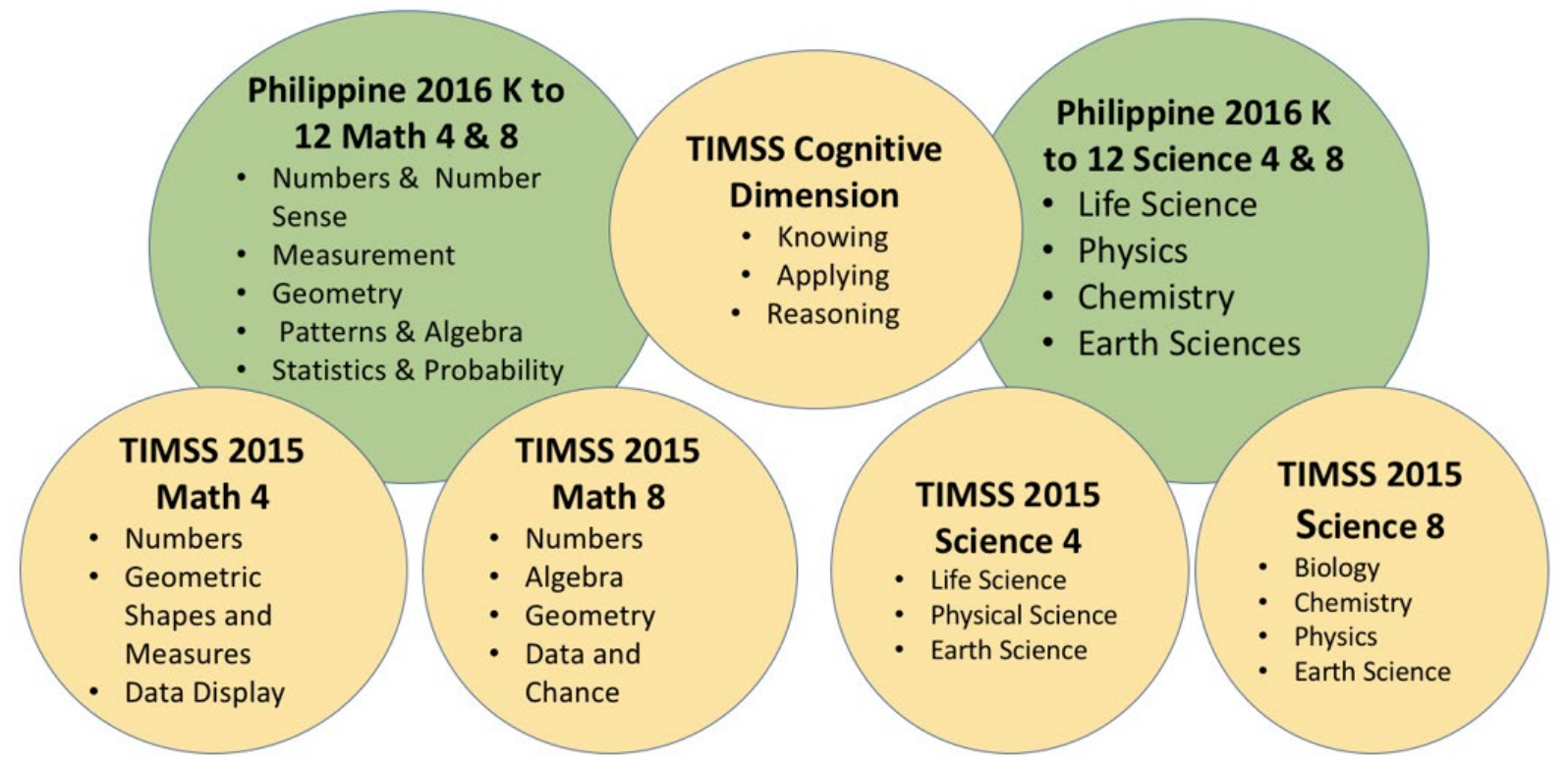

Figure 1. Mapping of the Philippine K to 12 Math \& Science vis-à-vis TIMSS 2015 Math \& Science Framework

3) Physics (25\%); and 4) Earth Science (20\%). The cognitive dimensions are: 1) knowing, which addresses the students' ability to recall, recognize, and describe facts, concepts, and procedures that are necessary for a solid foundation in science; 2) applying, which focuses on using knowledge to generate explanation and solve practical problems; and 3) reasoning, which includes using evidence and science understanding to analyze, synthesize, and generalize often in unfamiliar situations and complex contexts (Jones, Wheeler, \& Centurino, 2013, p 60). Both Grade 4 and 8 Science use the same cognitive dimensions in the assessment just like that in Mathematics but the distribution of items differs. In Science Grade 4, same as in Mathematics, knowing and applying weighed $40 \%$, and reasoning weighed 20\%. In Science Grade 8, the distribution is 35\% for knowing, 35\% for applying, and 30\% for reasoning.

Figure 1 shows how the researchers conceived this study. As shown, the content and cognitive domains in the TIMSS 2015 in Mathematics and Science Grade 4 and 8 were mapped with those in the Philippine K to 12 Intended Curriculum in Mathematics and Science. It was assumed that the degree of alignment of the two documents could predict readiness of the Philippines should it participate again in TIMSS.

\section{METHODOLOGY}

The study was a qualitative investigation of web-based curriculum documents. Bowen (2009), describes this qualitative research inquiry as document analysis where the functions of documents as a data source are examined. In this study, subject area experts examined the alignment between the two curriculum documents to identify possible gaps. Mathematics and Science for Grade 4 (Gronmo, Lindquist, Arora, \& Mullis, 2013: 11-24) and Grade 8 reported in the TIMSS 2015 Assessment Report (Jone, Wheeler, \& Centurino, 2013: 29-54) were mapped against the $2016 \mathrm{~K}$ to 12 Mathematics and Science Curriculum of DepEd. To the Great Schools Partnership (2013), this process is called curriculum mapping as it entails indexing or diagramming a curriculum to identify and address gaps, redundancies, and misalignments for purposes of improving the overall coherence of a course of study and its effectiveness.

In doing the document analysis or curriculum mapping, three content specialists per subject area were trained and guided on the process. Two independent experts did the mapping and reported analyses in a matrix form. A third expert was engaged to check and validate the work of the two other experts. Heat mapping, which is a technique in representing data graphically using the system of color coding of different values (Wikipedia, 2018) or a tool in visualizing data (Juneau, 2015) was done. In this study, four color codes were used to indicate levels of alignment in content domains: green, yellow, orange and no color. A competency in the K to 12 that is shaded green means it is fully matched with TIMSS in the same grade level. If coded yellow, it means the competency is covered at a lower level. If orange, the competency is covered in a higher level, which would signify that they were not developed yet at the time of assessment. If the competencies in TIMSS 2015 Framework were not shaded, this means they were not covered in the curriculum document. In terms of the cognitive dimensions, the content experts also 
used a matrix for analysis where all the competencies in the $\mathrm{K}$ to 12 Curriculum in Mathematics and Science were classified according to the three cognitive domains of knowing, applying, and reasoning in TIMSS.

There were four matrices prepared, one per subject area and per grade level. Triangulation technique was applied in this exercise where the content experts did their document analyses separately and independently then their work were compared to test the reliability of analysis. The degree of agreement in the analyses of two independent content experts per subject area in their mapping of all competencies in the documents was 85\% (for Science) and 90\% (Mathematics). Such percentage of agreement is considered high. For the competencies where the two hired content experts per area differed in their analyses, the third content expert adjudicated their analyses and finalized the categorization of competencies according to cognitive dimensions.

To determine the percentage of content competencies in Mathematics and Science Curriculum that were aligned to the TIMSS 2015 assessment competencies, the total number of competencies as stated in the TIMSS 2015 Framework for each subject area was the basis for the computation. To determine the distribution of competencies in the $\mathrm{K}$ to 12 Curriculum according to the cognitive dimensions, a simple percentage score was computed to represent competencies that are classified into knowing, applying and reasoning.

\section{RESULTS AND DISCUSSIONS}

\section{Alignment of TIMSS 2015 Grade 4 Mathematics Assessment Framework vis-à-vis Philippine 2016 K to 12 Mathematics Curriculum}

\section{Domain 1: Numbers}

This domain covered three (3) topics to include Whole Numbers; Fractions and Decimals; and Expressions, Simple Equations, and Relationships (Gronmo, Lindquist, Arora, \& Mullis, 2013).

Whole Numbers. Whole numbers in the TIMSS 2015 covered five (5) competencies: 1) demonstrating knowledge of place value; writing numbers in expanded form; representing numbers in words, diagrams and symbols; 2 ) comparing, ordering and rounding whole numbers; 3) computing with the four operations with whole numbers; 4) solving problems set in contexts including those involving measurements, money and simple operations; and 5) identifying odd and even numbers and multiples and factors of numbers (Gronmo, Lindquist, Arora, \& Mullis, 2013). All the TIMSS Math Grade 4 competencies on whole numbers were mapped with the Philippine K to 12 competencies in Mathematics in the same grade level. The alignment of whole number competencies in the Philippine curriculum with TIMSS 2015 is good for the country compared to what other countries have reported like Turkey and New York State claiming that these competencies have been covered starting grade one to higher grade levels (Incikabi, Ozgelen, \& Tjoe, 2012).

Fractions and Decimals. Fractions and decimals in TIMSS 2015 covered three (3) competencies: 1) recognizing fractions as parts of wholes, parts of a collections, or locations on number lines, and represent fractions using words, number, or models; 2) identifying equivalent simple fractions; comparing and ordering simple fractions; adding and subtracting simple fractions, including those set in problem situations; and 3) demonstrating knowledge of decimal place value including representing decimals using words, numbers, or models; comparing, ordering, and rounding decimals; adding and subtracting decimals, including those set in problem situations (Gronmo, Lindquist, Arora, \& Mullis, 2013). When these competencies were mapped with the Philippine K to 12 competencies, the first competency was mapped in Grade 1 to 4 and the rest in the same grade level. The $100 \%$ alignment of the TIMSS Grade 4 competencies on fractions and decimals to the Grade 4 curriculum is good but studies have reported that items on fractions usually are found difficult to the students (Wijaya, 2017).

Expressions, Simple Equations, and Relationships. Expressions, Simple Equations, and Relationships in the TIMSS 2015 covered three (3) competencies, namely: 1) finding the missing number or operation in a number sentence (e.g., $17+\mathrm{w}=29$ ); 2) identifying or writing expressions or number sentences to represent problem situations involving unknowns; and 3) identifying and using relationships in a well-designed pattern (e.g., describe the relationship between adjacent terms and generate pairs of whole numbers given a rule) (Gronmo, Lindquist, Arora, \& Mullis, 2013). All competencies were mapped with the same grade level in the Philippine curriculum. This means that when the Filipino Grade 4 students are assessed in TIMSS Mathematics, the competencies under Number Domain should not cause any difficulty to them as they are covered in their curriculum.

\section{Domain 2: Geometric Shapes and Measures}

This domain covered two (2) topics to include Points, Lines, and Angles; and Two- and Three-Dimensional Shapes (Gronmo, Lindquist, Arora, \& Mullis, 2013). 
Points, Lines, and Angles. There were four (4) competencies under this dimension: 1) measuring and estimating lengths; 2) identifying and drawing parallel and perpendicular lines.; 3) identifying, comparing, and drawing different types of angles (e.g., a right angle, and angles larger or smaller than a right angle); and 4) using informal coordinate systems to locate points in a plane (Gronmo, Lindquist, Arora, \& Mullis, 2013). All the first three competencies were found in the same grade level except for competency 4 , which was not covered in the curriculum in the elementary level. The introduction to the coordinate system was introduced in Grade 8 Mathematics and not in the Grade 4 or lower grades. Items on this competency in the TIMSS assessment are expected to be difficult then for the students as they have not been exposed to this competency in their current grade.

Two- and Three-dimensional Shapes. Three (3) competencies were covered: 1) using elementary properties to describe and compare common two- and three-dimensional geometric shapes, including line and rotational symmetry; 2) relating three-dimensional shapes with their two-dimensional representations; and 3) calculating perimeters of polygons, areas of squares and rectangles, and estimating areas and volumes of geometric figures by covering with a given shape or by filling with cubes (Gronmo, Lindquist, Arora, \& Mullis, 2013). Among these three competencies, the first competency was developed from Grade 2 to 4 of the K to 12 while the two competencies were covered in the same grade level.

\section{Domain 3: Data Display}

This domain covered only one (1) topic and that is Reading, Interpreting, and Representing.

Reading, Interpreting, and Representing. The two (2) competencies under this topic mapped with Grade $4 \mathrm{~K}$ to 12 Mathematics and these are: 1) reading, comparing, and representing data from tables, pictographs, bar graphs, line graphs and pie charts; and 2) using information from data displays to answer questions that go beyond directly reading the data displayed (Gronmo, Lindquist, Arora, \& Mullis, 2013).

In summary, of the 20 listed competencies (11 from Number Domain, 7 from Geometric Shapes and Measures Domain, and 2 from Data Display Domain) in the TIMSS 2015 Grade 4 Mathematics, 90\% were mapped to the target grade, $5 \%$ mapped in a lower grade and $5 \%$ is not covered. The competency on the introduction to the coordinate system in Geometric Shapes and Measures Domain is developed in Grade 8 Mathematics, which could be a problematic area to Grade 4 students when Philippines participates in TIMSS. In terms of the cognitive dimensions, about $9 \%$ of the competencies in the $\mathrm{K}$ to 12 curriculum are classified as knowing domain, 58\% are under applying domain, and $33 \%$ are under reasoning domain. This means that the students should be able to cope with the content and cognitive demands of the assessment as all the dimensions in the TIMSS are aligned with the curriculum.

\section{Alignment of TIMSS Grade 8 Mathematics Competencies vis-à-vis Philippine 2016 K to 12 Mathematics Curriculum}

\section{Domain 1: Number}

This domain covers three topics to include Whole Numbers; Fractions, Decimals, and Integers; and Ratio, Proportion, and Percent (Gronmo, Lindquist, Arora, \& Mullis, 2013).

Whole Numbers. Three (3) competencies covered in TIMSS 2015 Grade 8 were: 1) demonstrating one's understanding of whole numbers and operations (e.g., the four arithmetic operations; place value; and the commutative, associative, and distributive properties); 2) computing with whole numbers in problem situations; and 3) finding and using multiples or factors of numbers, identifying prime number, and evaluating powers of numbers and square roots of perfect squares up to 144 (Gronmo, Lindquist, Arora, \& Mullis, 2013). These competencies were developed in the curriculum from elementary to Grade 8.

Fractions, Decimals, and Integers. Two (2) competencies covered in TIMSS 2015 Grade 8 were: 1) identifying, comparing, or ordering rational numbers (fractions, decimals, and integers) using various models and representations (e.g., number line); and knowing that there are numbers that are not rational; 2) computing with rational numbers including those set in problem situations (Gronmo, Lindquist, Arora, \& Mullis, 2013). These two competencies were developed in the curriculum from elementary to Grade 8.

Ratio, Proportion, and Percent. Three (3) competencies covered in TIMSS 2015 Grade 8 were mapped as well in the $\mathrm{K}$ to 12 Mathematics and these are: 1) identifying and finding equivalent ratios; and modeling a given situation by using a ratio and divide a quantity in a given ratio; 2) converting among percents, proportions, and fractions; and 3) solving problems involving percents or proportions (Gronmo, Lindquist, Arora, \& Mullis, 2013). 


\section{Domain 2: Algebra}

This domain covered three (3) topics to include: 1) Expressions and Operations; 2) Equations and 3) Inequalities; and Relationships and Functions (Gronmo, Lindquist, Arora, \& Mullis, 2013).

Expressions and Operations. Three (3) competencies in TIMSS were covered in Grade 8 curriculum and these are: 1) finding the value of an expression given values of the variables; 2) simplifying algebraic expressions involving sums, products, and powers of expressions; and comparing expressions to determine if they are equivalent; and 3) using expressions to represent problem situations (Gronmo, Lindquist, Arora, \& Mullis, 2013).

Equations and Inequalities. Two (2) competencies in TIMSS were covered in Grade 8 curriculum and these are: 1) writing equations or inequalities to represent situations; and 2) solving linear equations, linear inequalities, and simultaneous linear equations in two variables (Gronmo, Lindquist, Arora, \& Mullis, 2013).

Relationships and Functions. Three (3) competencies in TIMSS were covered in Grade 8 curriculum and these are: 1 ) generalizing pattern relationships in a sequence, or between adjacent terms, or between the sequence number of the term and the term, using numbers, words, or algebraic expressions; 2) interpreting, relating and generating representations of functions in tables, graphs, or words; and 3) identifying functions as linear or non-linear; contrast properties of functions from tables, graphs, or equations; and interpreting the meanings of slope and y-intercept in linear functions (Gronmo, Lindquist, Arora, \& Mullis, 2013).

\section{Domain 3: Geometry}

This domain covered three (3) topics to include: 1) Geometric Shapes; 2) Geometric Measurement; and 3) Location and Movement (Gronmo, Lindquist, Arora, \& Mullis, 2013).

Geometric Shapes. Five (5) competencies in TIMSS 2015 were covered in Grade 8 curriculum and these are: 1) identifying different types of angles and use the relationships between angles on lines and in geometric figures; 2 ) identifying geometric properties of two- and three-dimensional shapes, including line and rotational symmetry; 3 ) identifying congruent triangles and quadrilaterals and their corresponding measures; and identifying similar triangles and use their properties; 4) relating three-dimensional shapes with their two-dimensional representations (e.g., nets, two-dimensional views of three-dimensional objects); and 5) using geometric properties, including the Pythagorean Theorem, to solve problems (Gronmo, Lindquist, Arora, \& Mullis, 2013).

Geometric Measurement. The three (3) competencies in TIMSS 2015 are: 1) drawing and estimate the size of given angles, line segments, and perimeters; and estimate areas and volumes; 2 ) selecting and using appropriate measurement formulas for perimeters, circumference, areas, surface areas, and volumes; and 3) finding measures of compound areas (Gronmo, Lindquist, Arora, \& Mullis, 2013). The first two (2) competencies are found in Grade 4-6 curriculum. However, the third TIMSS competency on finding the measures of compound areas is not explicitly stated in the K to 12 Curriculum. This means that should Filipino Grade 8 students take the TIMSS, they may have difficulty in answering items on finding the measures of compound areas as such competency is not explicitly defined in the $\mathrm{K}$ to 12 Curriculum they were exposed to.

Location and Movement. The two (2) competencies in TIMSS 2015 Math Grade 8 are: 1) locating points and solving problems involving points in the Cartesian plane; and 2) recognizing and using geometric transformations (translations, reflection, and rotation) of two-dimensional shapes (Gronmo, Lindquist, Arora, \& Mullis, 2013). Both competencies are not fully covered in the K to 12 Curriculum.

\section{Domain 4: Data and Chance}

This domain covered three (3) topics to include characteristics of data sets, data interpretation, and chance (Gronmo, Lindquist, Arora, \& Mullis, 2013).

Characteristics of Data Sets. Two (2) competencies covered in TIMSS 2015 Math Grade 8 are: 1) identifying and comparing characteristics of data sets including mean, median, mode, range, and shape of distributions (in general terms); 2) calculating, using, or interpreting mean, median, mode, or range to solve problems (Gronmo, Lindquist, Arora, \& Mullis, 2013). The two competencies were found in Grade 7 but the first competency was not fully covered as the topic on shapes of the distribution was not explicitly stated in the $\mathrm{K}$ to 12 Curriculum.

Data Interpretation. Three (3) competencies covered in TIMSS 2015 Math Grade 8 are: 1) reading data from a variety of visual data displays; 2) using and interpreting data sets to solve problems (e.g., make inferences, draw conclusions, and estimate values between and beyond given data points); and 3) identifying and describing approaches to organizing and displaying data that could lead to misinterpretation (e.g., inappropriate grouping, and misleading or distorted scales) (Gronmo, Lindquist, Arora, \& Mullis, 2013). The first two competencies mapped with Grades 5 to 8 curriculum while the last competency was not explicitly covered in the K to 10 Curriculum. 
Chance. The three (3) competencies in TIMSS 2015 are: 1) judging chances of outcomes as certain, more likely, equally likely, less likely or impossible in general terms; 2) using data, including experimental data, to estimate the chances of future outcomes; and 3) determining the chances of possible outcomes given a process designed to be random (Gronmo, Lindquist, Arora, \& Mullis, 2013). Two (2) competencies were found in Grade 8 while the second was partially covered in Grade 5.

In summary, for the whole Grade 8 Mathematics, out of the 34 competencies ( 8 from the Number Domain, 8 from Algebra Domain, 10 from Geometry Domain, and 8 from Data and Chance Domain) only 30 or $88 \%$ mapped with Grade 8 and lower grades while 4 or $12 \%$ were not explicitly covered in the Curriculum. In terms of the cognitive dimensions in TIMSS, 7\% of the competencies were classified as under knowing, 79\% are under applying, and 14\% are under reasoning. The result could indicate difficulty should the Filipino students take the TIMSS in Math Grade 8 due to the gaps in content and cognitive dimension particularly that on reasoning.

\section{Alignment of TIMSS 2015 Assessment Framework Grade 4 Science vis-à-vis Philippine $2016 \mathrm{~K}$ to 12 Science Curriculum}

\section{Domain 1: Life Science}

This domain covered five (5) topics to include: 1) Characteristics and Life Processes of Organisms; 2) Life Cycles, Reproduction, and Heredity; 3) Organisms, Environment, and their Interactions; and 4) Ecosystems; and 6) Human Health (Jone, Wheeler, \& Centurino, 2013).

Characteristics and Life Processes of Organisms. All the 10 competencies in TIMSS 2015 were covered in Grades 3 and 4 . Two (2) focused on the differences between living and non-living things; three (3) on physical and behavioral characteristics of major groups of animals; two (2) on functions of major structures in living things; and three (3) on responses of living things to environmental concerns (Jone, Wheeler, \& Centurino, 2013).

Life Cycles, Reproduction, and Heredity. All the six (6) competencies in TIMSS 2015 were covered also in Grades 3 and 4 Curriculum. Three (3) focused on the stages of life cycles and differences among the life cycles of common plants and animals and three (3) competencies on inheritance and reproduction strategies (Jone, Wheeler, \& Centurino, 2013).

Organisms, Environment, and their Interactions. The two (2) competencies in TIMSS 2015 on physical features or behaviors of living things that help them survive in their environment were covered in Grade 4 science curriculum (Jone, Wheeler, \& Centurino, 2013).

Ecosystems. All the eight (8) competencies in TIMSS 2015 about ecosystems were covered in Science Grade 4 curriculum. Two (2) competencies are on how plants and animals obtain energy; two (2) are on relationships in a simple food chain; two (2) are on interactions among living things in a community; and two (2) competencies on the impact of humans on the environment (Jone, Wheeler, \& Centurino, 2013).

Human Health. Looking at the TIMSS science framework in Jone, Wheeler, and Centurino (2013), all the three (3) competencies about transmission, symptoms, and prevention of communicable diseases and two (2) competencies on ways of maintaining good health were also covered in Grades 3 and 4 Curriculum.

\section{Domain 2: Physical Science}

The three (3) content dimensions in TIMSS 2015 under Physical Science include 1) classification and properties of matter and changes in matter; 2) forms of energy and energy transfer; and 3) forces and motion (Jone, Wheeler, \& Centurino, 2013).

Classification and Properties of Matter and Changes in Matter. There 11 competencies under this topic in the TIMSS science framework (Jone, Wheeler, \& Centurino, 2013). The two (2) competencies on states of matter and characteristic differences of each state were both covered in Grade 3. However, only one of the three (3) competencies on physical properties as a basis for classifying matter is covered. Two (2) other competencies were covered in grades higher than Grade 4 and these are on identifying properties of metals and on describing examples of mixtures and how they can be physically separated. The two (2) competencies on magnetic attraction and repulsion are both covered in Grades 3 and 4. For the physical changes observed in everyday life, the three (3) competencies are all covered. Finally, also covered in Grade 4 is the competency on chemical changes observed in everyday life. In total, six (6) competencies are covered in Grade 3, three (3) competencies are covered in Grade 4, and two (2) competencies are covered in levels higher than Grade 4.

Forms of Energy and Energy Transfer. There are eight (8) competencies under this topic in the TIMSS science framework (Jone, Wheeler, \& Centurino, 2013). The competency on common sources and uses of energy, that is, identifying sources of energy, such as the sun, water, wind, coal, oil, and gas, and understanding that energy is 
needed to move objects and for heating and lighting were covered in Grade 3. The two (2) competencies on light and sound in everyday life were both covered in Grade 4 . The two (2) competencies on heat transfer were covered as well. However, the three (3) competencies of electricity and simple electric systems were covered in Grade 5.C

Forces and Motion. Based on the TIMSS science framework (Jone, Wheeler, \& Centurino, 2013), the two (2) competencies were both covered such as: 1) identifying gravity as the force that draws objects to Earth; 2) recognizing that forces (pushing and pulling) may cause and object to change its motion and compare the effects of forces of different strengths in the same or opposite direction acting on an object.

\section{Domain 3: Earth Science}

The three (3) content dimensions under Earth Science include 1) Earth's Structure, Physical Characteristics, and Resources; 2) Earth's Processes and History; and 3) Earth in the Solar System (Jone, Wheeler, \& Centurino, 2013).

Earth's Structure, Physical Characteristics, and Resources. Based on the TIMSS science framework (Jone, Wheeler, \& Centurino, 2013), one (1) competency on the physical characteristics of the Earth system was covered, that is recognizing that Earth's surface is made up of land and water in unequal proportions (more water than land) and is surrounded by air; and describe where fresh and salt water are found. However, recognizing that wind and water change Earth's landscape was covered in Grade 5. For the Use of Earth's Resources, two (2) competencies were both covered in Grade 4 Science and these are: 1) identifying some of Earth's resources that are used in everyday life such as water, wind, soil, forests, oil, natural gas, and minerals; and 2) explaining the importance of using Earth's resources responsibly. However, the competency on explaining how features of Earth's landscape, such as mountains, plains, deserts, rivers, lakes, and oceans, affect human activities, such as farming, irrigation, and land development was covered in Grade 5. In summary, out of the five (5) competencies under this domain, two (2) are covered in Grade 4, one (1) in Grade 3, and two (2) in Grade 5.

Earth's Processes and History. With reference to the TIMSS science framework (Jone, Wheeler, \& Centurino, 2013), two (2) competencies about water on Earth and in the air were both covered in the curriculum. Moreover, two (2) competencies on daily, seasonal, and historical processes on Earth were covered. One (1) competency was not covered and this is about recognizing that some remains (fossils) of animals and plants that lived on Earth a long time ago are found in rocks and make simple deductions about changes in Earth's surface from the location of these remains.

Earth in the Solar System. Based on the TIMSS science framework (Jone, Wheeler, \& Centurino, 2013), the first competency on objects in the solar system and their movements was covered. However, the $2^{\text {nd }}$ competency was not covered, and this is about recognizing that the Moon revolves around Earth, and from Earth it looks different at different times of the month. On Earth's motion and related patterns observed on Earth, the first competency was covered in Grade 3. However, the $2^{\text {nd }}$ competency that is on explaining how seasons in the northern and southern hemispheres are related to Earth's annual movement around the Sun was covered in higher grades.

In summary, out of the 66 competencies (31 competencies under Life Science, 21 competencies under Physical Science, and 14 competencies under Earth Science) covered by the TIMSS assessment, only 37 or about $56 \%$ of the competencies in the K-12 curriculum are reflected in Grade 4 Science Curriculum, 19 or 29\% is covered in Grade 3, nine (9) or $14 \%$ is covered in higher grades, and one (1) or $1 \%$ is not explicitly reflected in the curriculum. This means that only 56 or about 85\% of the TIMSS 2015 Assessment in Science Grade 4 were covered explicitly by the Philippine's curriculum in Grades 3 to 4 Science. In terms of the cognitive domains, 19\% of the competencies are classified to be under knowing, $54 \%$ is under applying and $27 \%$ are under reasoning. This means that there are gaps in the Grade 4 curriculum in terms of content but not necessarily in the cognitive requirements of the TIMSS Science Grade 4 .

\section{Alignment of TIMSS 2015 Assessment Framework for Grade 8 Science vis-à-vis Philippine $2016 \mathrm{~K}$ to 12 Science Curriculum}

\section{Domain 1: Biology}

The six (6) topics under Biology include 1) Characteristics and Life Processes of Organisms; 2) Cells and Their Functions; 3) Life Cycles, Reproduction, and Heredity; 4) Diversity, Adaptation, and Natural Selection; 5) Ecosystems; and 6) Human Health (Jone, Wheeler, \& Centurino, 2013).

Characteristics and Life Processes of Organisms. With reference to the TIMSS science framework (Jone, Wheeler, \& Centurino, 2013), the two (2) competencies about the differences among major taxonomic groups of organisms and the three (3) competencies on structure and function of major organ systems were covered in the grades lower than Grade 8. However, the two (2) competencies on physiological processes of animals were covered 
in Grade 10. This means that of the five (5) competencies under this dimension of Biology, none are developed in Grade 8.

Cells and Their Functions. Looking at the TIMSS science framework (Jone, Wheeler, \& Centurino, 2013), all the four (4) competencies under structure and function of cells are developed in Grades 7 while the two (2) competencies on processes of photosynthesis and cellular respiration were covered in Grade 9 . Similar to the earlier dimension of Biology, none from the 6 competencies under this dimension on cells and their functions were covered in Grade 8.

Life Cycles, Reproduction, and Heredity. Based on the TIMSS science framework (Jone, Wheeler, \& Centurino, 2013), the two (2) competencies under life cycles and patterns of development were covered in the elementary level. The competency on sexual reproduction and inheritance in plants and animals particularly that on recognizing that sexual reproduction involves the fertilization of an egg cell by a sperm cell to produce offspring that are similar but not identical to either parent is covered in Grade 7 while relating the inheritance of traits to organisms passing on genetic material to their offspring is covered in Grade 8. However, the competency on distinguishing inherited characteristics from acquired or learned characteristics is not developed in the $\mathrm{K}$ to 10 document.

Diversity, Adaptation, and Natural Selection. Looking at the TIMSS science framework (Jone, Wheeler, \& Centurino, 2013), the two competencies on variation as the basis for natural selection were partially covered in Grades 7 and 8 but further elaborated in higher grades. However, the two competencies on fossils as evidence for changes in life on Earth over time are developed when one reaches Grade 10. In summary, out of the four (4) competencies under this dimension, none is fully developed in Grade 8.

Ecosystems. With reference to the TIMSS science framework (Jone, Wheeler, \& Centurino, 2013) the three (3) competencies on flow of energy in ecosystems were all covered in Grade 8. Similarly, the two (2) competencies on cycling of nutrients in ecosystems were also covered in Grade 8. However, the three competencies on interdependence of populations of organisms in an ecosystem were all covered in Grade 7 and so with the two competencies on factors affecting population size in an ecosystem. In other words, all the 10 competencies drawn from the dimension of ecosystem were covered either in Grade 8 or in a lower grade.

Human Health. Based on the TIMSS science framework (Jone, Wheeler, \& Centurino, 2013), one (1) competency on causes, transmission, prevention, and resistance to diseases is developed in Grade 8 or lower and further elaborated in Grade 9, that is, describing causes, transmission, and prevention of common diseases, such as in influenza, measles, malaria, and HIV. However, the competency on describing the role of the body's immune system in resisting disease and promoting healing is not developed in Grade 8 or in lower grades. The competency on the importance of diet, exercise, and lifestyle in maintaining health are both covered in Grade 8 or lower and Grade 9. The competency on identifying the dietary sources and role of nutrients in a healthy diet (vitamins, minerals, proteins, carbohydrates, and fats) is developed in Grade 8. In Summary, for the four competencies under Human Health, only one (1) competency is developed in the Grade 8 while the rest are developed in many grades if not at all.

\section{Domain 2: Chemistry}

The three (3) topics under Chemistry include 1) Composition of Matter; 2) Properties of Matter; and 3) Chemical Change (Jone, Wheeler, \& Centurino, 2013).

Composition of Matter. With reference to the TIMSS science framework (Jone, Wheeler, \& Centurino, 2013), the two (2) competencies on elements, compounds, and mixtures are developed in Grade 6 to 9. The two (2) competencies on the structure of atoms and molecules are covered in Grade 8, such as 1) describing the structure of matter in terms of particles (atoms and molecules); and 2) describing atoms as composed of subatomic particles (electrons surrounding a nucleus containing protons and neutrons). However, the competency on describing the molecules as combinations of atoms, such as $\mathrm{H} 2 \mathrm{O}, \mathrm{O} 2$, and $\mathrm{CO} 2$ is developed in Grade 9. In summary, of the five (5) competencies on composition of matter, only three (3) were covered in Grade 8 or lower while two (2) are not yet developed by the time the students take TIMSS Grade 8.

Properties of Matter. Looking at the TIMSS science framework (Jone, Wheeler, \& Centurino, 2013), of the three (3) competencies on physical and chemical properties of matter, only the competency on relating uses of materials to their physical properties, such as melting point and boiling point, and the ability to dissolve many substances, and thermal conductivity is developed in Grade 8. The competency on relating uses of materials to their chemical properties, such as rusting and flammability is developed in Grades 9 and 10 while distinguishing between physical and chemical properties of matter is not explicitly developed in the curriculum. The two competencies on physical and chemical properties as a basis for classifying matter are developed in different grade levels and so with the four competencies of mixtures and solutions and three (3) competencies of properties of acids and bases, which are mostly emphasized in Grade 7. 
Chemical Change. Based on the TIMSS science framework (Jone, Wheeler, \& Centurino, 2013), all the three (3) competencies on characteristics of chemical changes, two on matter and energy in chemical changes and one (1) on chemical bonds are all developed in grades higher than Grade 8. In other words, none of the six competencies on chemical change is developed in Grade 8.

\section{Domain 3: Physics}

The five (5) topics under Physics include 1) Physical States and Changes in Matter.; 2) Energy Transformation and Transfer.; and 3) Light and Sound; 4) Electricity and Magnetism; and 5) Forces and Motion (Jone, Wheeler, \& Centurino, 2013).

Physical States and Changes in Matter. Looking at the TIMSS science framework (Jone, Wheeler, \& Centurino, 2013), the two (2) competencies on motion of particles in solids, liquids, and gases are developed starting Grade 8 although they are further enhanced in higher grades. The three (3) competencies under changes in the state of matter are covered in Grade 8 or lower. However, the competency on explaining that mass remains constant during physical changes, such as change of state, dissolving solids, and thermal expansion is developed in Grade 10.

Energy Transformation and Transfer. Based on the TIMSS science framework (Jone, Wheeler, \& Centurino, 2013), the competency on forms of energy and the conservation of energy pertaining to identifying different forms of energy (kinetic, potential, mechanical, light, sound, electrical, thermal, and chemical) is developed in Grades 6 and 8. However, the competency on describing common energy transformations, such as combustion in an engine to move a car, photosynthesis, or the production of hydroelectric power and recognize that the total energy of a closed system is conserved is introduced in Grades 5 and then elaborated in Grade 9. Similarly, the three (3) competencies on heat transfer and thermal conductivity of materials are introduced from Grades 7 to 9 .

Light and Sound. With reference to the TIMSS science framework (Jone, Wheeler, \& Centurino, 2013), properties of light (transmission through different media; finite speed; reflection, refraction, absorption, and splitting of white light into its component colors) is introduced in Grade 8. The competency on relating the apparent color of objects to reflected or absorbed light is introduced in Grade 8 and then further developed in Grade 10. However, the two competencies, such as: 1) solving practical problems involving the reflection of light from plane mirrors and the formation of shadows; and 2) interpreting simple ray diagrams to identify the path of light and to locate images produced by lenses and mirrors (real images only) are developed in Grade 10. The three competencies on Properties of Sound are all introduced in Grade 8 or a lower grade. N C E.

Electricity and Magnetism. Based on the TIMSS science framework (Jone, Wheeler, \& Centurino, 2013), all the three (3) competencies on conductors and the flow of electricity in electrical circuits are developed in Grade 8 or lower grades. However, for the topic on Properties and Uses of Magnets and Electromagnets, this is introduced from Grades 3 to 10. The competency on describing uses of permanent magnets and electromagnets in everyday life, such as in a compass, doorbell, or recycling factory is developed in Grade 10.

Forces and Motion. Looking at the TIMSS science framework (Jone, Wheeler, \& Centurino, 2013), all the competencies under Common Forces and their Characteristics are introduced in Grade 8 or lower. For the effects of forces, however, demonstrating basic knowledge of how simple machines function, such as levers and ramps is introduced in Grade 6 but the three (3) competencies, namely: 1) explaining pressure in terms of force and area; and 2) describing effects related to pressure, such as atmospheric pressure decreasing with altitude, water pressure increasing with depth, and evidence of gas pressure in balloons; and 3) explaining floating and sinking in terms of density differences and the effect of buoyant force are not explicitly stated in the curriculum if not developed in the grades higher than Grade 8. On the other hand, the three (3) competencies on Motion and Changes in Motion are all introduced to students in Grade 8.

\section{Domain 4: Earth Science}

The four (4) topics under Earth Science include 1) Earth's Structure and Physical Features; 2) Earth's Processes, Cycles, and History; and 3) Earth's Resources, Their Use and Conservation; and 4) Earth in the Solar System and the Universe (Jone, Wheeler, \& Centurino, 2013).

Earth's Structure and Physical Features. With reference to the TIMSS science framework (Jone, Wheeler, \& Centurino, 2013), the four (4) competencies on Physical characteristics of Earth's surface and two (2) competencies on Components of Earth's atmosphere and atmospheric conditions are developed in grades lower than Grade 8.

Earth's Processes, Cycles, and History. Based on the TIMSS science framework (Jone, Wheeler, \& Centurino, 2013), the three (3) competencies under geological processes during Earth's history are developed in Grade 5 to 9. The two competencies on Earth's water cycle are developed in Grades 4 to 10. The three competencies on weather and climate are developed in grades lower than Grade 8. However, identifying or describing possible causes and/or 
sources of evidence for climate changes, such as those that occur during ice ages or that are related to global warming is developed in Grade 9, which is learned after the students have taken Grade 8.

Earth's Resources, Their Use and Conservation. Looking at the TIMSS science framework (Jone, Wheeler, \& Centurino, 2013), the four (4) competencies on managing Earth's resources are introduced in Grade 4 to 8 . The two competencies on land and water use are developed in Grade 9 or higher and these are: 1) explaining how common methods of land use, such as farming, logging, or mining can affect land and water resources; 2) explaining the importance of water conservation, and describe how purification, desalinization, and irrigation ensure that fresh water is available for human activities.

Earth in the Solar System and the Universe. Based on the TIMSS science framework (Jone, Wheeler, \& Centurino, 2013), the competency on observable phenomena on Earth resulting from movements of Earth and the Moon, which is, distinguishing between the effects of Earth's daily rotation about its axis and its annual revolution around the Sun, including how Earth's rotation and revolution relate to the appearance of constellations in the sky is not explicitly stated in the intended curriculum. The two other competencies under this dimension are developed in Grades 6 and 7. For the two competencies on Features of Earth, the Moon, and other planets, both are covered in Grade 6.

In Summary, out of the 119 stated competencies covered (36 in Biology, 23 in Chemistry, 34 in Physics, and 26 in Earth Science), 21 or $18 \%$ is developed in Grade 8 of the Philippine Science Curriculum, 52 or $44 \%$ is developed below Grade 8, 42 or 35\% is developed after Grade 8, and 4 or 3\% is not explicitly stated from Grade 3 to Grade 10 of the curriculum. This means that 73 competencies or about $61 \%$ of the TIMSS 2015 Assessment in Science Grade 8 is learned by the Filipino students in Grade 8 or in lower grades based on the intended science curriculum. However, in terms of the cognitive dimensions, $6 \%$ of the competencies in Science 8 curriculum are classified under knowing, $71 \%$ are under applying, and $23 \%$ are under reasoning. Given the significant number of the competencies in TIMSS 2015 Grade 8 Science that are not explicitly reflected in the curriculum and the lower percentage of reasoning among the competencies, it would be difficult to assume that the Filipino students would be ready to perform well in TIMSS Science Grade 8 in 2019 should the framework for assessment is the same as in 2015.

\section{CONCLUSIONS AND RECOMMENDATIONS}

Summary of the Study: The study intends to determine the extent of alignment of the 2015 TIMSS Assessment Framework with the Philippine K to 12 Curriculum in Mathematics and Science released in the DepEd's website in 2016, which is the reference of all instructional and assessment materials developed for use of schools in the Philippines. The results of the document analysis reveal that TIMSS 2015 Assessment Framework in Mathematics is more aligned with the intended curriculum of the Philippine Grade 4 Mathematics Curriculum (i.e. 95\% aligned) than that of the Grade 8 Mathematics Curriculum (i.e. about 88\% aligned). TIMSS 2015 Assessment Framework in Science is more aligned with the intended curriculum of the Philippine Grade 4 Science Curriculum (i.e. about $85 \%$ aligned) than that of the Grade 8 Science Curriculum (i.e. about $61 \%$ aligned). As a whole, the K to 12 Curriculum in Mathematics is more aligned with TIMSS 2015 Framework than that in Science. In terms of cognitive dimensions demanded by the TIMSS assessment, the Filipino students are trained in their curriculum on the domains of knowing and applying but not enough for reasoning both in Mathematics and Science Grade 8.

Implications: The results imply that the Filipino students could better participate in 2019 TIMSS Mathematics and Science Grade 4 than in Grade 8 as a possible gauge of the effectiveness of the K to 12 Reform. The results have also implications to the following: a) curriculum developers, as adjustments or enrichment in the curriculum should be done particularly in Mathematics and Science to give equal emphasis to those competencies in the TIMSS that are not captured by the present $\mathrm{K}$ to 12 Curriculum; b) instructional designers, as intervention programs to promote students' development and address their needs should be implemented particularly in the areas in the mathematics and science assessment framework in TIMSS 2015 that are not covered in the K to 12 Curriculum to make the performance of the Filipino students comparable with international standards; c) training providers, like the Philippine Normal University, the National Center for Teacher Education, as there is a need to design and implement continuing development programs that should allow teachers and education leaders to update and deepen their content knowledge and pedagogical skills particularly in the delivery of instruction in mathematics and science curriculum that are emphasized in international large-scale assessments; d) learning solutions providers, like Rex Group of Companies, as there is a need to produce learning, teaching and assessment materials that should not only be K to 12-compliant but also internationally-benchmarked, accessible to all Filipino children, and could develop globally competitive students; and e) decision makers, particularly those in the DepEd, as they need to set appropriate actions to make the Filipino students cognitively ready should the Philippines pursue participation in TIMSS 2019.

Limitations: The study focused only on the alignment of 2015 TIMSS in Mathematics and Science Grades 4 and 8 and it did not cover TIMSS Numeracy and TIMSS Advanced as there were no clear documents to examine to 
understand these assessments at the time of investigation. The investigation covered only the cognitive assessment and failed to capture the surveys to students, teachers and school heads. Other international large-scale assessments like Program for International Reading and Literacy Survey (PIRLS) and Program for International Student Assessment (PISA) were not also included in the analysis though they could also provide possible indicators of the effectiveness of the educational reform. Finally, the reference for mapping in this study was the TIMSS 2015 Assessment Framework as the TIMSS 2019 Assessment Framework (Mullin \& Martin, 2017) was not out yet at the time this study was conducted.

Suggestions for Future Studies: Given the limitations of the study, it is recommended that future studies be focused on the analysis of the TIMSS Numeracy and TIMSS Advanced to deepen the analysis of the results. Other international large-scale assessments like PIRLS and PISA should also be investigated as to how they match with the Philippine Curriculum in making the quality of the educational system in the Philippines comparable with international standards. An analysis of the alignment of the Philippine K to 12 Curriculum to the TIMSS 2019 Framework is also encouraged to verify the degree of cognitive preparedness of the Filipino students in meeting the standards set in large-scale assessment considering its goal of making the Filipino students globally competitive. Other countries who intend to participate in TIMSS could also replicate the methodology of this study as preparation to participation in international large-scale assessment.

\section{REFERENCES}

Bowen, G. A. (2009). Document analysis as a qualitative research method. Qualitative Research Journal, 9(2), 27-40. https:/ / doi.org/10.3316/QRJ0902027

Department of Education (2018). Senior High School Program. Retrieved from www.deped.gov.ph

Department of Education (April, 2015). DepEd Order No.8 s. 2015 “Policy guidelines on classroom assessment for the $\mathrm{k}$ to 12 basic education program. Retrieved from www.deped.gov.ph

Department of Education (August, 2016). K to 12 Curriculum Guide in Mathematics Grades 1 to 10. Retrieved from www.deped.gov.ph

Department of Education (August, 2016). K to 12 Curriculum Guide in Science Grades 3 to 10. Retrieved from www.deped.gov.ph

Department of Education (January, 2015). DepEd Memorandum No.2 s.2015 on the Technical working group on the assessment system of the K to 12 program. Retrieved from www.deped.gov.ph

Department of Education (June, 2016). DepEd Order No.55 s. 2016 Policy guidelines on the national assessment of student learning for the $\mathrm{k}$ to 12 basic education program. Retrieved from www.deped.gov.ph

Department of Education (June, 2017). DepEd Order No.29 s. 2017 Policy guidelines on system assessment in the k to 12 basic education program. Retrieved from www.deped.gov.ph

Great Schools Partnership (2013). Glossary of education reform. Retrieved from https://www.edglossary.org/curriculum-mapping/

Gronmo, L. S., Lindquist, M., Arora, A., \& Mullis, I. V. S. (2013). TIMSS 2015 Mathematics Framework. In I. Mullis, \& M. Martin (Eds.) TIMSS 2015 Assessment Frameworks (11-24). United States: TIMSS \& PIRLS International Study Center, Lynch School of Education, Boston College, and International Association for the Evaluation $\begin{array}{llll}\text { of Educational } & \text { Achievement } & \text { (IEA). }\end{array}$ https:/ / timssandpirls.bc.edu/timss2015/frameworks.html

Incikabi, L., Ozgelen, S., \& Tjoi, H. (2012). A comparative analysis of numbers and biology content domains between Turkey and USA. International Journal of Environmetal \& Science Education, 7(4), 523-536.

Jone, L. R., Wheeler, G., \& Centurino, V. A. S. (2013). TIMSS 2015 Science Framework. In I. Mullis \& M. Martin (Eds). TIMSS 2015 Assessment Framework (29-54). United States: TIMSS \& PIRLS International Study Center, Lynch School of Education, Boston College and International Association of for the Evaluation of Educational Achievement. Retrieved from https:/ / timssandpirls.bc.edu/timss2015/frameworks.html

Juneau, P. (2015). Quantification of Heat Map Data Displays for High- Throughput Analysis. Journal of Pharmacogenomics \& Pharmacoproteomics, 6(2), 146. https:/ / doi.org/10.4172/2153-0645.1000146

Mullis, I. V. S. (2013). TIMSS 2015: 20 Years of Monitoring Trends. In I. Mullis \& M. Martin (Eds). TIMSS 2015 Assessment Framework (3-4). United States: TIMSS \& PIRLS International Study Center, Lynch School of Education, Boston College and International Association of for the Evaluation of Educational Achievement. Retrieved from https://timssandpirls.bc.edu/timss2015/frameworks.html

Mullis, I. V. S., \& Martin, M. O. (2017). TIMSS 2019 assessment frameworks. TIMSS and PIRLS International Study Center, Lynch School of Education, Boston \& International Association for the Evaluation of Educational Achievement. 
Ogena, E. B., Laña, R. D., \& Sasota, R. S. (2010). Performance of Philippine high schools with special curriculum. In the 2008 Trends In International Mathematics and Science Study (TIMSS-Advanced). Retrieved from www.nap.psa.gov.ph

Ogena, E. O., Brawner, F. G., \& Ibe, M. D. (2013). Preparing teachers of Mathematics in the Philippines. In J. Schwille, L. Ingvarson, \& R. Holdgreve-Resendez (Eds), TEDS- M Encyclopedia, a guide to teacher education context, structure and quality assurance in 17 countries, findings from the IEAteacher education and development study in Mathematics. Amsterdam, Netherlands: International Association for the Evaluation of Educational Achievement (IEA).

Republic of the Philippines (2013). Republic Act No. 10533 known as An Act Enhancing the Philippine Basic Education System by Strengthening its Curriculum and Increasing the Number of Years for Basic Education, Appropriating Funds Therefor and for Other Purposes. Retrieved from http:/ / www.officialgazette.gov.ph/2013/05/15/republic-act-no-10533

Republic of the Philippines. (2012). Republic Act No. 10157 known as An Act Institutionalizing the Kindergarten Education into the Basic Education System and Appropriating Funds Therefor. Retrieved from www.lawphil.net

Wijaya, A. (2017). The difficulties of indonesian fourth graders in learning fractions: An early exploration of TIMSS 2015 Results. American Institute of Physics. https:// doi.org/10.1063/1.4995154

Wikipedia (2018). Heat map. Retrieved from https:/ / en.wikipedia.org/wiki/Heat_map

\section{http://www.ejmste.com}

